\title{
COMPARISON OF EXTRAPERITONEAL AND TRANSPERITONEAL RADICAL CYSTO- PROSTATECTOMY IN TERMS OF FIRST 30 DAYS OUTCOMES
}

\author{
Mudassar Sajjad, Qamar Zia*, Haroon Sabir**, Faran Kiani***, Muhammad Nawaz ${ }^{* * *}$, Sohail Raziq****, Bilal Habib**** \\ Combined Military Hospital Malir/National University of Medical Sciences (NUMS) Pakistan, *Combined Military Hospital Lahore/National University of \\ Medical Sciences (NUMS) Pakistan, **Pakistan Naval Ship Shifa Hospital, Karachi Pakistan, ***Armed Forces Institute of Urology/National University of Medical \\ Sciences (NUMS) Rawalpindi Pakistan, ${ }^{* * * *}$ Combined Military Hospital Sialkot/National University of Medical Sciences (NUMS) Pakistan, \\ *****Pakistan Institute of Medical Sciences, Islamabad Pakistan
}

\begin{abstract}
Objective: To compare the first 30-day outcomes of Trans-peritoneal and Extra-peritoneal Radical cysto-prostatectomy. Study Design: Quasi-experimental study.

Place and Duration of Study: Armed Forces Institute of Urology, Rawalpindi, from Mar 2015 to Mar 2019.

Methodology: A total of 100 patients who underwent Radical cystoprostatectomy were observed in two groups either by extra or trans-peritoneal approach. Patients diagnosed with carcinoma urinary bladder (both muscle and non-muscle invasive) vetted through multidisciplinary meeting, with or without neo-adjuvant chemotherapy were included. Patients undergoing salvage cystectomy or any previous open abdomino-pelvic surgery were excluded. The standard techniques were used for both approaches. Variables under study were recorded for first 30-day-followup period.

Results: The mean age was $59.9 \pm 7.231$ years (range=34-80). In extra-peritoneal group the mean duration of surgery was $5.6 \pm 1.16$ hours comparing to $7.2 \pm 1.34$ hours in the trans-peritoneal group. Statistically significant trend was also noted in the favour of extra-peritoneal group for stay in Intensive care in post-operative period ( $3.00 \pm 1.19$ days $/ 4.77 \pm 1.20, p<0.001)$ as well total stay in the hospital $(6.06 \pm 2.8$ days/ $11.74 \pm 4.17, p<0.001)$. Overall comparison of total number of complications as per Clavien-Dindo system in both groups was insignificant $(p=0.136)$, however a significant trend in favour of extraperitoneal group was noted with respect to major wound dehiscence as well rate of blood transfusion $(p<0.001)$.

Conclusion: Extra-peritoneal approach showed a favourable trend in terms of operative time and early recovery after radical cysto-prostatectomy.
\end{abstract}

Keywords: Bladder, Bladder neoplasm, Cystectomy, Cysto-prostatectomy, Ileal conduits, Ureterostomy, Urinary diversion.

This is an Open Access article distributed under the terms of the Creative Commons Attribution License (https://creativecommons.org/licenses/by-nc/4.0/), which permits unrestricted use, distribution, and reproduction in any medium, provided the original work is properly cited.

\section{INTRODUCTION}

Bladder cancer is one of the debilitating diseases and is the second most common cancer of genitourinary origin and the tenth most common cancer diagnosed worldwide 1 . Alone in the United states more than 81 thousand people were diagnosed with it in 2018, while more than 17 thousand died².

Among various treatment-options for muscle invasive bladder cancer (MIBC) and non-muscle invasive bladder cancer (NMIBC), radical cystectomy (RC) and urinary diversion are considered as the gold standard treatment ${ }^{3}$. RC can be performed by a conventional trans-peritoneal or a relatively newer extra-peritoneal approach coupled with either ileal conduit or neobladder as a diversion. RC with either diversion is considered as an extensive operation. Like other major operations it does possess significant morbidity and mortality ${ }^{4}$, and its complications of first 30 days have been reported in the range of $31.5-58 \% 5,6$. Kulkarni et $a l^{7}$, first introduced the extra-peritoneal approach in

Correspondence: Dr Qamar Zia, Classified Urologist, Combined Military Hospital, Lahore Pakistan

Received: 20 Apr 2020; revised received: 02 Sep 2020; accepted: 09 Sep 2020
2002. It has been considered as a superior technique in comparison to trans-peritoneal in terms of complications like paralytic ileus, wound dehiscence and reoperation rate ${ }^{8}$. Raza et $a^{9}$, observed a mortality of $4.5 \%$ in their cohort of RC with conventional intra peritoneal technique.

In Pakistan very few centers are performing RC regularly. The conventional Intra-peritoneal technique with ileal conduit is more popular because of simplicity, safety and reproducibility in the hands of urological surgeons with varying degree of expertise ${ }^{10}$. The relatively newer extraperitoneal approach is performed less frequently in urology centers. In our center extraperitoneal radical cysto-prostatectomy programme was started in 2014. This study has prospectively compared this relatively newer extra-peritoneal technique with conventional trans-peritoneal in regards to various variables including operating time, peri and postoperative complications including blood loss, total duration of stay in Intensive care, total hospital stay and first 30 days mortality.

\section{METHODOLOGY}

For this prospective study we obtained approval 
from local ethical committee (IRB/AFIU-164/2015). It was a quasi-experimental study and conducted at the department of Urology in Armed Forces Institute of Urology (AFIU), Rawalpindi. The duration of study was from March 2015 to March 2019.

Patients included in this study were diagnosed cases of carcinoma bladder requiring cystectomy. All patients were discussed in Multidisciplinary team meeting in the presence of oncologist, radiologist and histopathologist along with urologists which is held weekly at our centre AFIU. All participants were recruited after taking informed consent and they completed question-naire that included demographic information, date of diagnosis, histopathological grade and receiving of any neo-adjuvant chemotherapy. Patients were placed in one of the two groups; group 1 underwent extra-peritoneal radical cysto-prostatectomy while group-2 included patients who had same procedure through transperitoneal approach.

Inclusion criteria consisted of only male patients of any age diagnosed with bladder cancer and vetted through multidisciplinary meetings. Patients of both muscle invasive and non-muscle invasive bladder cancer were included. Neo-adjuvant chemotherapy did not affect the inclusion of patients. Patients requiring salvage cystectomy and those with previous abdomino-pelvic surgery were excluded. Various procedures were used as diversion methods for urine for example, ileal conduit, bladder substitution and cutaneous ureterostomy but in this study only patient with ileal conduits were recorded.

The sample size was calculated online ${ }^{10}$. by the help of following study ${ }^{12}$, a total of 113 patients were recruited however ${ }^{13}$, were excluded due to a lack of sufficient follow-up data, thus leaving 100 patients for post-operative follow-up. Among those 53 were operated through extra-peritoneal (group-1) while remaining 47 underwent surgery via trans-peritoneal approach (group- 2) by purposive non-probability sampling technique.

All patients were admitted two days prior to the surgery and underwent bowel preparation with only clear fluids. They were given phosphate enema night before surgery. Patients were kept nil by mouth 12 hours prior to surgery. Antibiotics as per hospital policy, Cefoperzone \pm Sulbactam and Metronidazole, were administered intravenously at the time of induction. TED stockings were used in all patients.

In group 1 patients, a lower midline incision was made. Space of Retzius were entered remaining extra- peritoneal and bilateral spermatic cord clipped and excised. Peritoneum was swept cephalad over the psoas muscle using both sharp and blunt dissection to expose iliac vessels and ureters. Both ureters were slinged using rubber sloops. Then self-retaining retractors were used for retraction. Extended lymph node (LN) dissection was performed. Dissection along the lateral aspect continued to identify the superior vesical pedicel and entrance of ureters into the intra-mural part of bladder. At this point endo-pelvic fascia was opened and pubo-prostatic ligaments were taken down. Dorsal venous plexus was ligated and divided using diathermy between ligatures. Membranous urethra exposed and anterior half divided to expose the retained catheter before dividing it completely. Plane between rectum and prostate developed sparing the Denonvillier's fascia. Retrograde dissection continued to expose the seminal vesicles. The two pillars of bladder divided and peritoneum entered to include urachus in the specimen. For urinary diversion ileal conduit was constructed using Wallace 1966 technique.

Conventional trans-peritoneal technique was performed by midline laparotomy and recto-vesical plane developed and ante-grade dissection done. In most of the cases internal iliac artery was ligated after its first division. Superior and inferior vesical pedicles ligated and divided. Prostatic dissection performed in the last phase in ante-grade fashion. None of the patient in this group had neo-bladder construction so complete transaction of urethra and DVC done en bloc. Similar technique was used for urinary diversion.

Postoperatively both groups were monitored in our post-operative Intensive care unit for the first 24 hours. Pain was controlled by Intravenous opiates and non-opiates when available. Post-operative protocol included continuation of enoxaparin (40 mg subcutaneous), early mobilization, intravenous fluids and early oral feed. Complications were recorded and managed accordingly. Post-operative laboratory tests included daily serum renal functions, complete blood picture, liver function and ABGs when required.

Follow-up period was kept to 4 weeks and patients were seen every second week in this period when discharged to home. The data was recorded initially in Microsoft Excel (Microsoft Corp. Redmond, Washington) for the patients under study which included the name, age, date, date of diagnosis, position, indication \& technique of surgery (group), total duration of the procedure, perioperative and postoperative blood loss and need for any blood transfusion, procedure of 
diversion, time taken for radical cysto-prostatectomy, diversion and both combined. Postoperatively complications were noted as per Clavien-Dindo classification.

Variables under study were recorded for 30-dayfollowup period. Categorical variables were compared with proportions and Fischer's exact test-derived confidence interval $(\mathrm{CI})$ whereas continuous variables were compared with means and $95 \% \mathrm{CI}$ for parametric data and medians for nonparametric data. Statistical calculations were performed with SPSS- 23 and $p \leq 0.05$ were considered statistically significant.

\section{RESULTS}

Among 100 patients selected for the analysis, the average age was found to be $59.9 \pm 7.231$ years (range $=34-80$ ). The distribution of age and number of lymph nodes dissected by both techniques were found to be statistically insignificant (table-I). There was mixed type of cases in both groups, overall, $91 \%$ were muscle invasive and $9 \%$ were non-muscle invasive $(p=0.748$, table-I).

In group-1 patients (extra-peritoneal), the duration of surgery was $5.6 \pm 1.16 \mathrm{hrs}$ (range $=4.2-10 \mathrm{hrs}$ ) comparing to $7.2 \pm 1.34 \mathrm{hrs}$ (range $=4.2-12 \mathrm{hrs}$ ) in trans- peritoneal $(p<0.01)$. This trend of statistical significance was noted in the favour of extra-peritoneal group for 'stay in ICU too. $(p<0.01$ table-I).

The complications were diverse ranging from need for transfusion to the death of patient (table-II). There were five postoperative deaths: One patient in the extra-peritoneal died of pulmonary embolism and 3 in the trans-peritoneal group died, among those two were related to Myocardial infarction and one due to septic complications leading to multiple organ failure. The total number of early complications/major complications (grade 3-5) amounted to 24 for group 1 and 31 for group 2. The overall complication rate (percentage of patients with one or more complications) did not differ significantly between both groups $(p=0.136)$.

Repeat operations were carried out in 5 patients which included insertion of ante-grade ureteric stent, insertion of retrograde ureteric stent, revision of anastomotic leak and wound dehiscence. One patient was re-operated in the group 1 and 4 in group $2(p=0.184$, table-II). Significant difference in favour of extra-peritoneal approach was noted with respect to major wound dehiscence, paralytic ileus and need for blood transfusion (table-II).

Table-I: Comparison of observed variables in group $1 \& 2$.

\begin{tabular}{|c|c|c|c|}
\hline & $\begin{array}{l}\text { Group-1 }(\mathrm{n}=53) \\
\text { Extra-peritoneal cystectomy }\end{array}$ & $\begin{array}{c}\text { Group-2 }(\mathrm{n}=47) \\
\text { Trans-peritoneal cystectomy }\end{array}$ & $p$-value \\
\hline Age & $61 \pm 7.95($ range= $=34-75)$ & $58 \pm 6.201($ range $=49-80)$ & 0.129 \\
\hline Type of Carcinoma & $\begin{array}{c}\text { Non-muscle invasive }=6(11.3 \%) \\
\text { Muscle invasive }=47(88.6 \%)\end{array}$ & $\begin{array}{c}\text { Non-muscle invasive }=3(6.4 \%) \\
\text { Muscle invasive }=44(93.6 \%)\end{array}$ & $1.00^{*}$ \\
\hline \multirow{3}{*}{$\begin{array}{l}\text { Operative details } \\
\text { Duration (Hours) } \\
\text { lymph nodes removed }\end{array}$} & & & \\
\hline & $5.67 \pm 1.16$ (range $4.2-10$ ) & $7.2 \pm 1.34$ (range $4.2-12$ ) & $<0.001$ \\
\hline & $16.1 \pm 5.70($ range $=0-26)$ & $13.6 \pm 5.65($ range $=0-26)$ & 0.031 \\
\hline \multirow{2}{*}{$\begin{array}{l}\text { Post-operative details } \\
\text { Post op days in ITU } \\
\text { Stay in hospital (days) }\end{array}$} & & & \multirow[b]{2}{*}{$\begin{array}{l}<0.001 \\
<0.001\end{array}$} \\
\hline & $\begin{array}{l}3.00 \pm 1.193(\text { range }=2-7) \\
6.06 \pm 2.818(\text { range }=2-17)\end{array}$ & $\begin{aligned} 4.77 \pm 1.20(\text { range } & =3-8) \\
11.74 & \pm 4.17(\text { range }=3-23)\end{aligned}$ & \\
\hline Disposal from hospital ** & $\begin{array}{l}\text { Without complications }=44(83 \%) \\
\text { With complications }=8(15 \%)\end{array}$ & $\begin{array}{c}\text { Without complications }=37(78.7 \%) \\
\text { With complications }=5(10.6 \%)\end{array}$ & $0.179^{*}$ \\
\hline
\end{tabular}

${ }^{*}$ chi square test/ Fisher's exact test. ${ }^{* *}$ dead patients not included

Table-II: Comparison of complications.

\begin{tabular}{l|c|c|c}
\hline Type of complication & $\begin{array}{c}\text { Group-1 (n=53) } \\
\text { Extraperitoneal Cystectomy }\end{array}$ & $\begin{array}{c}\text { Group-2 (n=47) } \\
\text { Transperitoneal Cystectomy }\end{array}$ & $p$-value \\
\hline Blood transfusion (units) & $2.26 \pm 0.96($ range $=1-4)$ & $3.36 \pm 0.89($ range $=2-5)$ & $<0.001$ \\
\hline Duration of Ileus (days) & $1.98 \pm 1.11($ range $=1-6)$ & $3.57 \pm 0.92($ range $=2-6)$ & $<0.001$ \\
\hline Major wound dehiscence & - & $7(14.8 \%)$ & $0.004^{*}$ \\
\hline Surgical site infection & $1(1.8 \%)$ & $3(6.38 \%)$ & $0.339^{*}$ \\
\hline Intraabdominal abscess & - & $1(2.12 \%)$ & $0.470^{*}$ \\
\hline Bowel leak & - & $1(2.12 \%)$ & $0.470^{*}$ \\
\hline Reoperation & $1(1.8 \%)$ & $4(8.51 \%)$ & $0.184^{*}$ \\
\hline Urinary leak & $7(13.2 \%)$ & $5(10.6 \%)$ & $0.765^{*}$ \\
\hline
\end{tabular}

${ }^{*}$ Chi-square tests/ Fisher's exact test. $X=$ mean 
Table-III: Duration of Ileus in days.

\begin{tabular}{l|c|c|c}
\hline $\begin{array}{l}\text { Duration } \\
\text { of Ileus } \\
\text { in Days }\end{array}$ & $\begin{array}{c}\text { Group-1 (n=53) } \\
\text { Extraperitoneal } \\
\text { Cystectomy }\end{array}$ & $\begin{array}{c}\text { Group-2 (n=47) } \\
\text { Transperitoneal } \\
\text { Cystectomy }\end{array}$ & $\begin{array}{c}\boldsymbol{p} \text { - } \\
\text { value }\end{array}$ \\
\cline { 1 - 3 } None & $20(37.7 \%)$ & - & \multirow{2}{*}{$<0.001$} \\
\cline { 1 - 3 } 2 & $23(43.39 \%)$ & $5(10.63 \%)$ & \\
\cline { 1 - 3 } 3 & $4(7.54 \%)$ & $18(38.29 \%)$ & \\
\cline { 1 - 3 } 5 & $4(7.54 \%)$ & $17(36.17 \%)$ & \\
\hline 6 & $1(1.88 \%)$ & $6(12.76 \%)$ & \\
\hline
\end{tabular}

gut for longer duration but also minimizes its active handling.

This relatively newer approach for radical cystectomy is well known to many centers worldwide, but it was not very popular in our country. In our center, where this study was carried out, it became popular when urologists got hands on experience in the urooncology department of the Queen Elizabeth Hospital, Birmingham United Kingdom between 2012 and 2015.

Table-IV: comparison of variable with various studies.

\begin{tabular}{|c|c|c|}
\hline & Our study & Other studies \\
\hline Age (Mean \pm SD / Median \pm IQR) & $59.9^{*}(7.2)$ & $\begin{array}{c}\text { Raza et al }{ }^{10}=60.25^{*}(15.7) \\
\text { Gore } \text { et al } 1=74.5^{*}(5.5) \\
\text { Modi } \text { et al }{ }^{2}=75.4 \dagger(71.1-80.0) \\
\text { Serel et al } l^{14}=55 \dagger(46-70) \\
\text { Svatek et al }{ }^{3}=70 \dagger(62-75) \\
\text { Schiavina }{ }^{4}=69.2^{*}(9.1) \\
\text { Moschini }^{5}=61 \dagger(61-75)\end{array}$ \\
\hline $\begin{array}{l}\text { Average duration of procedure } \\
\text { (hours) }\end{array}$ & $\begin{array}{l}5.7(\mathrm{EP}) \\
7.2(\mathrm{TP})\end{array}$ & $\begin{array}{c}\text { Serel et al } 14=6.29(\mathrm{EP}), 6.75(\mathrm{TP}) \\
\text { Schiavina et al }{ }^{18}=6.1(\mathrm{TP})\end{array}$ \\
\hline Hospital stay in days (mean) & $\begin{array}{c}6.06^{*}(\mathrm{EP}) \\
11.74^{*}(\mathrm{TP})\end{array}$ & $\begin{array}{l}\text { Schiavina et al } 18=15.0(\mathrm{TP}) \\
\text { Semerjian et } a l^{6}=6.75\end{array}$ \\
\hline $\begin{array}{l}\text { Ileus } \\
\text { (days + No of patients) }\end{array}$ & $\begin{array}{l}1.98^{*}, 30 / 53(\mathrm{EP}) \\
3.57^{*}, 43 / 47(\mathrm{TP})\end{array}$ & $\begin{array}{c}\text { Serel et al } 14=2 / 48(\mathrm{EP}), 12 / 47(\mathrm{TP}) \\
\text { Schiavina et al } 18=36 / 161(\mathrm{TP}) \\
\text { Chang } \text { et al }{ }^{7}=11 / 44\end{array}$ \\
\hline $\begin{array}{l}\text { Wound dehiscence } \\
\text { (\% \& No of patients) }\end{array}$ & $14.8 \%(7 / 47)(\mathrm{TP})$ & $\begin{array}{c}\text { Schiavina et al } 18=11.8 \%(19 / 161)(\mathrm{TP}) \\
\text { Chang et al } 20=2 \%\end{array}$ \\
\hline $\begin{array}{l}\text { Wound infection } \\
\text { (\% \& No of patients) }\end{array}$ & $\begin{array}{l}0.53 \%,(1 / 53)(\mathrm{EP}) \\
1.41 \%,(3 / 47) \mathrm{TP}) \\
\end{array}$ & Serel et al $14=8.3 \%(4 / 48 \mathrm{EP}), 8.5 \%(4 / 47 \mathrm{TP})$ \\
\hline
\end{tabular}

\section{DISCUSSION}

Bladder cancer remains the second most common urological malignancy in the world ${ }^{11}$. Radical cystectomy along with pelvic lymphadenectomy, being the gold standard treatment for bladder cancer is performed by the surgeons very frequently. Despite many complications related to ante-grade trans-abdominal approach it is been practiced by most of the surgeons. The reason for those complications with trans-peritoneal approach is attributable to opening of peritoneum at the very start of the surgery, which leads to prolonged exposure of gut to the external environment ${ }^{12}$, and also breaks the normal compartmentalization in-between the gastrointestinal and urinary tract ${ }^{8}$. Among those complications, Paralytic ileus is very frequent, which seems to occur in up to $10-35 \%$ of the operated patients ${ }^{13}$. To reduce such complications extraperitoneal approach was developed, in which peritoneum is opened at the end of the surgery before fashioning he urinary diversion like ileal conduit ${ }^{14}$. Extraperitoneal approach not only reduces the exposure of
This study as per the design plan followed patients for 4 weeks only. In our cohort of population, the average age of patients was found to be around 59.9 years (mean). It was comparable with the local study done by Raza et al ${ }^{10}$, i.e. 60.25 years (mean). However, our patients were generally younger when comparing to the international data ${ }^{10,14-19}$.

The total combined average duration for surgery in both groups was 6.43 hours, which if seen group wise, has a difference of 1.5 hour in favour of extraperitoneal approach $(p<0.001)$. The reason was less duration is better handling of prostatic apex in relatively blood less field. Our duration is more comparing to various international studies, Serel et al, via extraperitoneal approach showed total duration of 4.3 hours while Schiavina et al via ${ }^{18}$, trans-peritoneal approach showed almost same duration. The reason of this difference of more than an hour can be because of use of time saving equipment like the use of endo-staplers for gut anastomosis and as well judicious use of other time saving techniques which were not easily available 
locally (thrombotic products like flowseal, hemolocks, ligaclips, ligasures, etc).

We documented the complications as per clavien Dindo system ${ }^{22}$. Worldwide there is a complication rate of $25-57 \%$ after radical cystectomy, our overall complication rate (percentage of patients with one or more complications) did not differ significantly between both groups. $(p=0.136)$. There were total of 5 postoperative deaths $(5 \%)$, which was not significant when seen group wise. Overall mortality rate for this procedure is documented at $3-5 \% 23$.

Post-operatively, in our cohort of patients, most complications were of grade 1 and 2. Most common complication was paralytic ileus which was recorded in days. In group 1, paralytic ileus persisted for 1.98 days (mean). Serel et al ${ }^{14}$, described ileus for 1 day in their extra-peritoneal cohort of patients, which corresponds very near to ours (table-IV).

The other major surgical complication which was seen in group 2 of our study was major wound dehiscence, seen in 7 patients $(14.8 \%$ of the total 47 patients) as compared to nil in the extra-peritoneal group $(p=0.004)$, it required secondary surgical procedures in 3 cases. Schiavina et al ${ }^{18}$, also mentioned $11.8 \%$ of their patients to have wound dehiscence who had transperitoneal cystectomy. The global incidence of wound infection (SSI) after radical cystectomy has been reported to range from $2.9-46 \%{ }^{24}$. We saw 3 patients in the trans-peritoneal while a single patient in extra-peritoneal group, whose wound was infected. $(p=0.339)$. The drains being source of surgical site infection ${ }^{25}$, were removed as soon as possible.

The rate of blood transfusion was significantly lower in group 1. The possible reason for this was meticulous ligation of dorsal venous complex (DVC) before division. As we had less ileus in the retro-peritoneal cohort of patients therefore their stay in intensive treatment centre as well overall stay in the hospital was less comparing to the trans-abdominal group. Twelve patients have urinary leak post-operatively in both groups with no statistical significant difference. Leak was managed expectantly mainly. Three patients required reoperation and revision of ureterileal anastomosis. The reported rate of urinary leak in international literature is $20(9-15 \%)$.

The difference in number of lymph nodes excised and involved were not statistically significant $(p=0.031$, table-I). However, we did see lymphocele for long duration in one patient in trans-peritoneal group, which later required CT guided placement of drain. Overall rate of lymphocele in our cases was very less due to meticulous surgery including clipping and ligation of lymphatic channels.

\section{LIMITATION OF STUDY}

Quasi-experimental design of this study was a limitation to reach a definitive conclusion; in our setup we cannot have more powerful study involving further randomization of patients for a particular technique.

We did not compare our data with the minimal invasive techniques of laparoscopy and robotics, as no center in our country is performing radical cystectomy by these techniques, which have shown clearly benefits and early post-operative recovery and 30-days complications. Further prospective randomized study can prove further the potential benefits and unearth the real value of the extra-peritoneal approach, which was briefly touched by our study.

\section{CONCLUSION}

Extra-peritoneal approach showed a favourable trend in terms of operative time and early recovery after radical cysto-prostatectomy. This however, needs further probe by randomized studies.

\section{CONFLICT OF INTEREST}

This study has no conflict of interest to be declared by any author.

\section{REFERENCES}

1. Yang LS, Shan BL, Shan LL, Chin P, Murray S, Ahmadi N, et al. A systematic review and meta-analysis of quality of life outcomes after radical cystectomy for bladder cancer. Surg oncol 2016; 25(3): 281-97.

2. Siegel RL, Miller KD, Jemal A. Cancer statistics, 2018. CA Cancer J Clin 2018; 68(1): 7-30.

3. Khan MS, Omar K, Ahmed K, Gan C, Van Hemelrijck M, Nair R. Long-term Oncological outcomes from an early phase randomised controlled three-arm trial of open, robotic, and laparoscopic radical cystectomy (CORAL). Eur Urol 2020; 77(1): 110-18.

4. Hu X, Xiong SC, Dou WC, Shao YX, Yang WX, Liu JB, et al. Minimally invasive vs open radical cystectomy in patients with bladder cancer: A systematic review and meta-analysis of randomized controlled trials. Eur J Surg Oncol 2020; 46(1): 44-52.

5. Johnson SC, Smith ZL, Golan S, Rodriguez JF, Smith ND, Steinberg GD. Temporal trends in perioperative morbidity for radical cystectomy using the National Surgical Quality Improvement Program database. Urol Oncol 2017; 35(11): e13- e19.

6. Bazargani ST, Djaladat H, Ahmadi H, Miranda G, Cai J. Gastrointestinal complications following radical cystectomy using enhanced recovery protocol. Eur Urol Focus 2018; 4(6): 889-94.

7. Kulkarni JN, Agarwal H. Transperitoneal vs. extraperitoneal radical cystectomy for bladder cancer: A retrospective study. Int Braz J Urol 2018; 44(2): 296-3.

8. Rowland RG. Complications of continent cutaneous reservoirs and neobladders-series using contemporary techniques. AUA Update Series 1995; 14(25): 201-5.

9. Raza SJ, Ather MH, Khan FA, Alam Z. Grading complication following radical cystectomy and ileal conduit for bladder cancer 
using Clavien grading system. J Coll Physicians Surg Pak 2012; 22(7): 448-51.

10. Sean P. Kane B. Sample size calculator. Available from: https:// clincalc.com/Stats/SampleSize.aspx.

11. Young MJ, Elmussareh M, Weston P, Dooldeniya M. Radical cystectomy in the elderly-Is this a safe treatment option?. Arab J Urol 2017; 15(4): 360-5.

12. Jentzmik F, Schostak M, Stephan C, Baumunk D, Lingnau A, Weikert $\mathrm{S}$, et al. Extraperitoneal radical cystectomy with extraperitonealization of the ileal neobladder: a comparison to the transperitoneal technique. World J Urol 2010; 28(4): 457-63.

13. Chang SS, Cookson MS, Baumgartner RG, Wells N, Smith JA. Analysis of early complications after radical cystectomy: results of a collaborative care pathway. J Urol 2002; 167(5): 2012-6.

14. Serel TA, Sevi NG, Perk H, Kosar A, Soyupek S. Antegrade extraperitoneal approach to radical cystectomy and ileal neobladder. Int J Urol 2003; 10(1): 25-8.

15. Gore JL, Litwin MS, Lai J, Yano EM, Madison R, Setodji C, et al. Use of radical cystectomy for patients with invasive bladder cancer. J Natl Cancer Inst 2010; 102(11): 802-11.

16. Modi PK, Hollenbeck BK, Oerline M, Weizer AZ, Montgomery JS, Kaffenberger SD, et al. Real-world impact of minimally invasive versus open radical cystectomy on perioperative outcomes and spending. Urol 2019; 125(1): 86-91.

17. Svatek RS, Fisher MB, Williams MB, Matin SF, Kamat AM, Grossman HB, et al. Age and body mass index are independent risk factors for the development of postoperative paralytic ileus after radical cystectomy. Urol 2010; 76(6): 1419-24.

18. Schiavina R, Borghesi M, Guidi M, Vagnoni V, Zukerman Z,
Pultrone C, et al. Perioperative complications and mortality after radical cystectomy when using a standardized reporting methodology. Clin Genitourin Cancer 2013; 11(2): 189-97.

19. Moschini M, Martini A, Zamboni S, Mattei A, Baumeister P, Di Bona $C$, et al. Evaluation of cause of death after radical cystectomy for patients with bladder cancer: the impact of age at the time of surgery. Clin Genitourin Cancer 2019; 17(3): e541-8.

20. Semerjian A, Milbar N, Kates M, Gorin MA, Patel HD, Chalfin $\mathrm{HJ}$, et al. Hospital charges and length of stay following radical cystectomy in the enhanced recovery after surgery era. Urol 2018; 111(1): 86-91.

21. Chang SS, Alberts G, Cookson MS, Smith Jr JA. Radical cystectomy is safe in elderly patients at high risk. J Urol 2001; 166(2): 938-41.

22. Clavien PA, Barkun J, De Oliveira ML, Vauthey JN, Dindo D, Schulick RD, et al. The clavien-dindo classification of surgical complications: five-year experience. Ann of Surg 2009; 250(2): 187-96.

23. Haroon N, Nadeem M, Ather MH. Age Adjusted Charlson Comorbidity Index: predictor of 90-day mortality after radical cystectomy. J Surg Oper Care 2016; 1(2): 204-8.

24. Kyoda Y, Takahashi S, Takeyama K, Masumori N, Tsukamoto T. Decrease in incidence of surgical site infections in contemporary series of patients with radical cystectomy. J Infect Chemother 2010; 16(2): 118-22.

25. Mangram AJ, Horan TC, Pearson ML, Silver LC, Jarvis WR. Guideline for prevention of surgical site infection, 1999. Hospital infection control practices advisory committee. Infect Control Hosp Epidemiol 1999; 20(1): 250-78. 